\title{
Strategies of Address in English Lingua Franca (ELF) Academic Interactions
}

\author{
Maicol Formentelli \\ Department of Humanities, University of Eastern Piedmont, Vercelli, Italy
}

Copyright $\subseteq 2018$ by authors, all rights reserved. Authors agree that this article remains permanently open access under the terms of the Creative Commons Attribution License 4.0 International License

\begin{abstract}
The paper describes the address practices reported by students and lecturers from three English-taught master's degrees organised at a small Italian university where English is used as a lingua franca (ELF) of communication. The main aim of the study is to ascertain whether and how the multilingual and multicultural composition of the ELF classroom influences participants in their choice of address strategies in English. The findings show two main patterns of address in the ELF courses: 1) an asymmetrical, non-reciprocal use of address strategies, in which lecturers take an informal and familiar stance (T-forms), while students tend to express deference and respect (V-forms); 2) a reciprocal, symmetrical use of $\mathrm{V}$-forms that encodes formality and mutual respect. While informality is promoted by lecturers as part of the policies of the master's programmes, some students and lecturers show resistance to the use of familiar address terms and favour formal strategies to convey respect to the interlocutor. The informants' comments recorded in the questionnaires reveal that participants' cultural backgrounds, previous experience in their home universities, and assumptions about the interlocutor's cultural expectations play a significant role in shaping address practices in ELF academic courses.
\end{abstract}

Keywords Address Practice, English Lingua Franca (ELF), Academic Interaction, Intercultural Communication, Deference, Informality, Formality

\section{Introduction}

Address practices, i.e. the way interpersonal relationships are linguistically built and maintained in interaction by means of personal pronouns, names, titles, honorifics or other nominal expressions, are a crucial aspect of human relations. By choosing or avoiding an address form, speakers set the level of social distance between one another, express admiration, respect, affection for the interlocutor, or conversely encode hostility, aggressiveness and antagonism.

Since the publication of Brown and Gilman's [1] seminal work, the complexity of address practices has been documented in several studies over the last fifty years, but this pervasive phenomenon still continues to be a fascinating challenge for scholars. Some research projects have attempted a comparative description of address strategies involving a large number of languages and language types. Adopting a sociolinguistic perspective, Braun [2] explores the use of address terms in about 30 languages to capture intralinguistic variation that is assumed to reflect the interlocutors' social characteristics and their relationship in the dyad. A typological approach is followed by Helmbrecht [3] in the World Atlas of Language Structures (WALS), where the author describes the codification of politeness in second person pronouns based on a sample of more than 200 languages and identifies the areal distribution of different honorific types. Recently, the attention has shifted to patterns of variation in pluricentric languages, i.e. languages with two or more codified national standards showing at least some distinctive norms [4], reporting significant findings on address practices in European languages including Dutch (e.g. [5,6]), English (e.g. [7-10]), German (e.g. [11-13]), Spanish (e.g. $[14,15])$ and Swedish (e.g. $[11,16,17])$.

The present paper deals with address practices in English, "the most pluricentric and international of all languages" [18, p. 99] and nowadays the main lingua franca in a wide range of domains of interaction. English lingua franca (ELF) encounters have been described as loci where co-operation, linguistic accommodation and situated negotiation of norms are crucial to guarantee successful communication despite the great variability of participants' linguacultural backgrounds and proficiency levels in English [19]. The aim of the study is to report on the patterns of address that may emerge in multilingual and multicultural contexts where English is chosen as lingua franca. The academic setting is regarded as a privileged domain to investigate ELF interactions, given the increasing number of English-taught programmes offered by non-Anglophone European universities and the effects 
of education policies aimed at attracting international students and teaching staff [20]. By focussing on the strategies of address reported by students and staff in ELF master's degrees organised at an Italian university, this case study will shed light on some of the patterns emerging in the negotiation of interpersonal relations in a growing intercultural environment.

\section{ELF in Higher Education and the Notion of Culture}

The spread of ELF in higher education is inextricably linked to the internationalisation of universities [21]. The turn of the millennium has seen a dramatic increase in English-medium instruction (EMI) programmes offered by universities throughout Europe and in particular in southern European countries including Italy [22-25]. ${ }^{1}$ This has promoted student and staff mobility across Europe and from countries all over the world and has led to a growing heterogeneity of the classrooms in terms of participants' linguistic and cultural backgrounds as well as communicative competence in English.

Numerous are the challenging aspects of the ELF classroom that may have an impact on address practice, starting from the notion of culture. In ELF teaching activities, English is not a mere instrument used to deliver subject contents or to exchange ideas, but is the language through which interpersonal relations are constructed and developed, personal identities are negotiated, and speakers' linguacultural backgrounds are foregrounded to establish common ground and build rapport [26].

Linguacultural aspects are crucial in address practices, as the choice of address terms is regulated by culturally-embedded sociopragmatic norms learnt by members of a community through primary and secondary socialization. The importance of such socially accepted norms becomes evident especially when speakers deliberately or accidentally deviate from the expected behaviour by using an inappropriate address term, with the risk of incurring social sanction and causing temporary or permanent disruption of relationships.

No total agreement has been reached yet among scholars on the role of participants' native cultures, and of Anglophone cultural models in shaping ELF communication. House [27] proposes the Culture Irrelevance Hypothesis, according to which ELF interactants fail to identify with English as a cultural symbol as much as they neglect references to their L1 culture in the on-going interaction. More plausibly, other hypotheses point to interference and transfer from one's

1 EMI is often used as a synonym for ELF, but the two terms show different nuances of meaning. The former is restricted to the academic domain and does not necessarily refer to highly intercultural settings; the latter is more generally applied to interactions where a variety of linguacultures get in contact [26, pp. 5-7]. native cultural and linguistic norms that signal cultural belonging or simply counterbalance lacks of communicative competence in English. An explicit way to express cultural belonging is for example code-switching to one's own L1 in ELF interactions [28,29], but also the adoption of L1 discourse strategies and interactional styles can be interpreted as a sign of cultural allegiance [30]. Similarly, Meierkord [31] advocates cultural hybridity to capture the dynamicity of ELF exchanges, where a new 'inter-culture' or 'third culture' is locally co-constructed and continuously negotiated among participants through processes of accommodation.

The notion of culture and cultural reference in ELF is made more complex by the changing composition of ELF exchanges, whose participants cannot be considered members of a speech communities in the traditional sense of a group of people converging towards a set of linguistic forms and social norms [32], but rather constitute communities of practice that share activities and goals on a temporary basis and may develop over time and through interactions a network of interpersonal relationships and a common repertoire of routines, words, attitudes, beliefs, behaviours, symbols, styles [33]. To what extent this shared repertoire of communicative practices also applies to address practices and norms in ELF academic interactions will emerge from the analysis of the questionnaires completed by students and faculty members.

\section{The English Address System}

Following the traditional distinction between $\mathrm{T}$-forms and $\mathrm{V}$-forms of address to indicate familiar/informal and polite/formal pronouns respectively [1], the English address system is summarised in Table 1 .

Table 1. The English address system

\begin{tabular}{|c|c|c|}
\hline T-FORM & & V-FORM \\
\hline & YOU & \\
\hline FIRST NAME, & & TITLE, \\
mate, guys, & & TITLE + LAST \\
dear, love,.. & NAME, \\
\hline
\end{tabular}

Unlike most of European languages, English does not codify formality/informality through a binary pronominal distinction between a $\mathrm{T}$ address pronoun and a $\mathrm{V}$ address pronoun, but only has the single second-person pronoun you, which has been often described as a pragmatically neutral address pronoun [11, p. 38] [34]. In English, speakers rather express interpersonal stance lexically, by means of either first names, familiarisers (e.g. mate, guys, buddy) and terms of endearment (e.g. love, dear, honey) that can be assimilated to T-forms, or honorifics (e.g. sir, madam, ladies), personal titles (e.g. Mr, Mrs, Ms) and professional titles (e.g. prof., Dr) with or without a last name that constitute the repertoire of $\mathrm{V}$-forms. 
The use of lexical address strategies in Anglophone academic settings is quite varied, as one would expect from a pluricentric and global language. As for the three major varieties of English, i.e. American English, British English and Australian English, Formentelli and Hajek [10] describe a generalised use of first names by lecturers when addressing students, interpreted as a way to establish a more familiar relationship in the classroom and to foster a favourable learning environment. Conversely, a more heterogeneous picture is provided of the address strategies employed towards the teaching staff. While Australian students report using first names as a default strategy [10], British informants are more likely to use $\mathrm{V}$-forms for a certain span of time and shift to T-forms usually after frequent contact and extended collaboration [7]. In American English, on the other hand, the teaching staff is generally addressed with academic titles or honorifics regardless of their teaching position, establishing a non-reciprocal, asymmetrical address pattern $[35,36]$.

\section{Address Strategies in ELF Academic Interactions}

\subsection{Methodology and Data}

In order to explore and describe patterns of address in ELF academic interactions, a questionnaire was distributed to students and lecturers of three English-taught master's degrees organised at a small university in northern Italy. Participants in the study come from various European and non-European countries and use English as the main lingua franca of communication both in teaching and learning activities and during socialization. Classrooms are highly heterogeneous in terms of linguacultural backgrounds, and the sample of informants includes more than 35 different nationalities and 25 different native languages, as indicated by participants themselves. ${ }^{2}$ Both genders are represented in the sample, with a majority of male lecturers and approximately the same number of male and female students; informants' age range spans from 23 to 41 years for students and from 29 to 69 years for lecturers and teaching assistants.

The first part of the questionnaire features closed questions in which informants are asked to select one or more address strategies employed to address lecturers/students both in face-to-face interaction and in email communication. In the second part, informants have

2 Participants come from Argentina, Belgium, Brazil, Bulgaria Cameroon, China, Colombia, Ecuador, France, Germany, Greece, Hungary, India, Iran, Italy, Kazakhstan, Macedonia, Mexico, Nepal, Pakistan, Palestine, Peru, Poland, Portugal, Rumania, Saudi Arabia, Serbia, Sudan, Switzerland, Tanzania, Turkey, Uganda, UK, US, Vanuatu Islands, Vietnam. to evaluate their relationships with lecturers/students in the ELF courses in terms of deference/respect, formality, informality, familiarity and distance. A glossary of terms is provided with the following definitions: deference/respect, i.e. the expression of regard and appreciation for the recipient's professional or social status, qualities and personality; formality, i.e. a serious, self-controlled behaviour typical of certain official and/or institutional encounters; informality, i.e. not formal or official, relaxed behaviour, suitable when you are with friends and family; familiarity, i.e. friendly behaviour that you develop after frequent and habitual contact; distance, i.e. not intimate, when people do not know each other well or do not have a close relationship.

To further explore participants' feelings about address practices in the ELF classroom, students and lecturers are also asked to take a position on the use of first names, which can be regarded as particularly risky in intercultural encounters and even more so in hierarchically-organised domains of interaction like universities [37]. A final open question concludes the survey, where informants can comment on aspects related to address practice based on their personal experience in the ELF courses and compare it with academic interactions in their home countries.

A total of 99 questionnaires were returned, 62 by students and 37 by lecturers. In what follows, the results of the survey are presented and discussed.

\subsection{Results}

\subsubsection{Students' Perspectives}

Students' responses on the strategies used in addressing lecturers and teaching assistants in ELF classroom interactions are summarised in Figure 1.

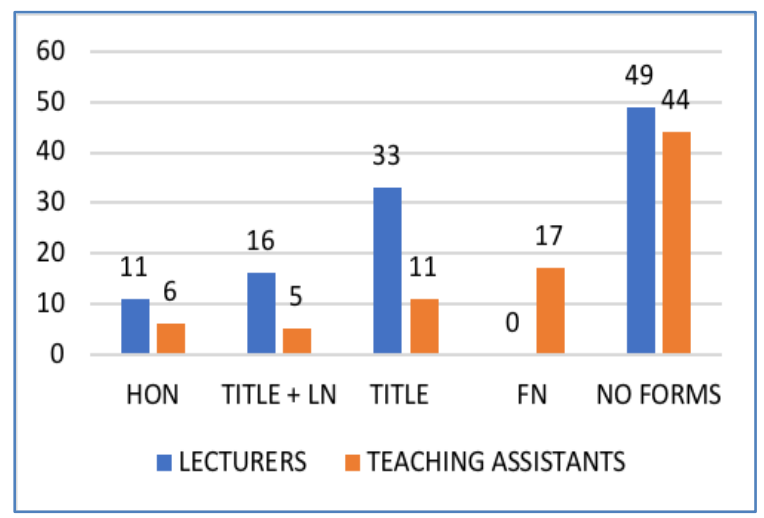

Figure 1. Address strategies to teaching staff in face-to-face interaction

When addressing lecturers, students show a general preference for $\mathrm{V}$-forms, choosing between the title professor or teacher (33 informants), the title prof./Dr followed by a last name (LN) (16 informants), and the honorifics (HON) sir and madam (11 informants). No T-forms (first name - FN) are reported. The majority of students (49 informants) also opt for not using address 
forms in class and getting their teachers' attention by means of phatic expressions like excuse me or by raising a hand. This avoidance strategy might be exploited as a deliberate way not to commit to the overt expression of any interpersonal stance.

The picture is slightly different when teaching assistants are addressed. While $\mathrm{V}$-forms are relatively frequently reported (title, 11 informants; honorific, 6 informants; title plus last name, 5 informants), T-forms emerge as the preferred lexical strategy (17 students). Teaching assistants are generally closer to master's students in terms of age and academic position and this may facilitate the use of first names in classroom exchanges. Again, however, the most frequently reported option is the avoidance of address forms (44 students).

Moving to address in email correspondence (Figure 2), results are in line with what is reported in face-to-face interactions. V-forms qualify as the default strategies chosen by students as opening formulae, with a dramatic increase in the combination title plus last name (52 students) and a corresponding drop in the use of T-forms (2 students), which may indicate that written communication is perceived as a more formal register.

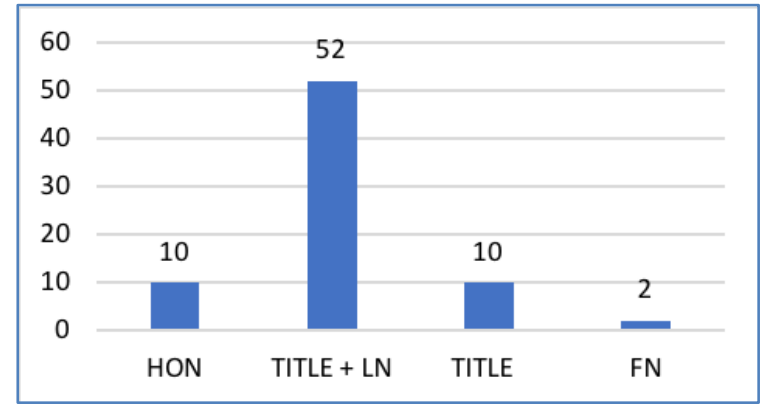

Figure 2. Address strategies to teaching staff in emails

The set of questions in the second part of the questionnaire is aimed at exploring students' perception of their relationship with teachers and the attitudes towards the use of first names in the ELF classroom. Figure 3 shows students' evaluations of classroom relations in terms of deference/respect, formality, distance, informality and familiarity.

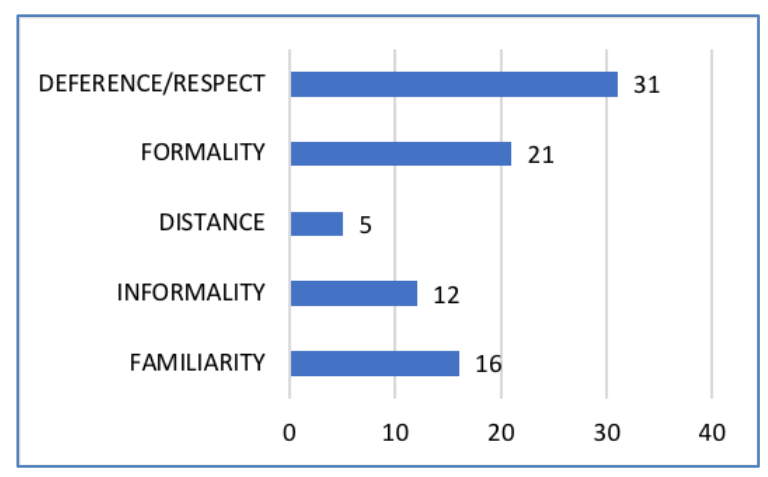

Figure 3. Students' perception of student/lecturer relationship

More than one option is sometimes selected by informants, as a reflection of the complex and dynamic nature of interpersonal relations. While deference/respect and formality stand out as the most frequently reported evaluations (31 and 21 students, respectively), at least one out of five students perceives the relationship with teachers as characterised by informality and familiarity (12 and 16 informants, respectively). Distance, on the other hand, does not seem to be experienced in classroom relations and is only reported by five students.

To capture students' attitudes towards the use of first names in the ELF classroom, two further questions are asked: a) Have any of your lecturers ever asked you to call them by their first name? b) How do you feel when lecturers call you by your first name? Students' responses to the two questions are plotted in Figure 4 and Figure 5.

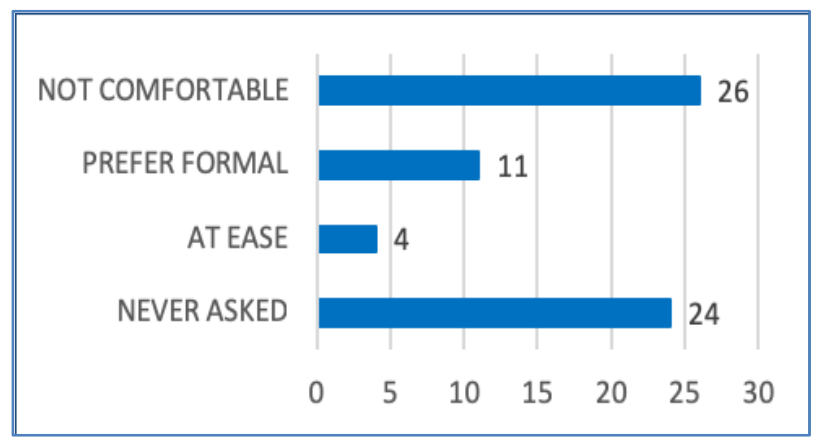

Figure 4. Students' attitudes towards first names to lecturers

The majority of students do not seem to welcome the use of first names in addressing their lecturers, even when lecturers themselves encourage the practice. 26 students report not feeling comfortable with using T-forms and 11 students declare a preference for more formal strategies. Only four students state that they feel at ease when calling lecturers by their first names. Some of the informants (24 students) report that lecturers never asked them to use their first names. The opinions emerging from Figure 4 confirm the distribution of address strategies summarised in Figure 1 , where $\mathrm{V}$-forms are strongly preferred to $\mathrm{T}$-forms.

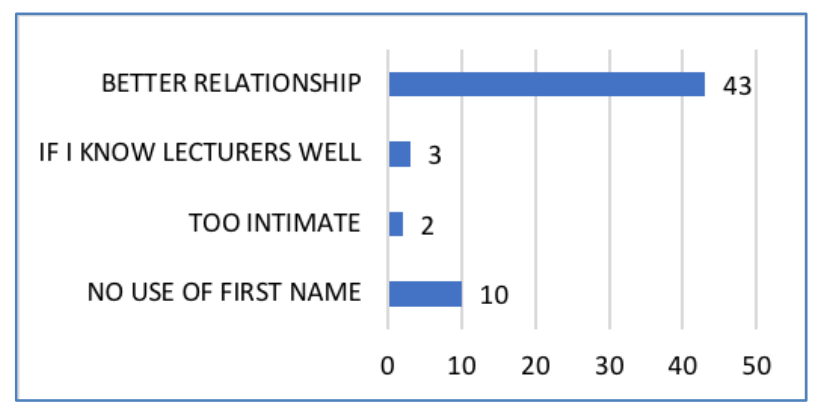

Figure 5. Students' perception of lecturers using first names

Completely different are students' attitudes towards the use of their first names on the part of lecturers (Figure 5). The great majority of students (43 informants) believe that being called by first name is indicative of a better relationship with their teachers and contributes to build 
rapport. Three students find it appropriate only when they know the lecturer well, while two students consider this address practice too intimate. A few informants (10 students) report that lecturers do not address them by their first name and avoid taking a position on the matter.

The final question of the survey allows us to further explore students' perspectives on the address practices reported in ELF courses, which are compared with the academic relations experienced in their home countries. One theme emerging from students' comments is the generalised informality in the Italian ELF courses, which is evaluated positively, as can be read in comments (1), (2) and (3).

(1) The interaction between teachers and students are informal in a way that is very easy to feel free to ask and intervene at any time. (Female student, Italy)

(2) I really appreciate that some professors are really accessible, always open to begin a conversation not only with respect of the course. [...] Usually the professor breaks the formality doing some jokes. (Female student, Peru).

(3) The lecturers are really nice. We have a lot of fun in class. In China some professors are really friendly, but some of them are quite seriously rigid. (Female student, China)

Other informants acknowledge a higher level of informality in ELF courses compared to interactions in their home universities, but are very critical of informal address practice (i.e. first names) towards lecturers, as in comments (4), (5) and (6).

(4) I address them always in a formal way [i.e. Sir, Madam, Dr+last name], avoiding to talk a lot and going straight to the point I want us to discuss. It is true they are more open here than in my country and more friendly too, but I think we are students and they are lecturers so always be formal. (Female student, Cameroon)

(5) First days I came here I thought how rude especially European students are to their lecturers. Then I realised this was the way they had been raised in their culture and I found similar opinions in Pakistanis guys too. In my country teachers are respected more. (Male student, Iran).

(6) Even though a master course has to be more informal, I don't feel comfortable to say first name only while addressing lecturers/professors. In Nepal we have more formality than here we call Sir, there's no way to call their first name, it's impossible over there. Here we can but I never practice this, I call them professor because I feel comfortable to say professor and even when I'm writing emails I address like Professor Bianchi or Professor Rossi. (Male student, Nepal)

In contrast, a few students offer the opposite evaluation of relationships in the Italian ELF courses and consider them much more formal compared to their home universities (comments 7 and 8).

(7) I think the approach of strategy applied by most of the lecturers in this master is not very convenient, because there is too much formality, which may be a problem to give way to a more enriching exchange of ideas and points of view. In my country, at the level of master course the relation student-lecturer is pretty horizontal. (Male student, Ecuador)

(8) In Australia it's less formal than here because here you have to say Doctor and their name or Professor and their name, whereas in Australia it is very easy going and laidback. We usually use lecturers' first name and address them by their first name even if they are doctor. (Female student, Vanuatu Islands)

The variety of viewpoints emerging from the comments above finds an explanation in the numerous variables that intervene in shaping interpersonal relations, which are often noticed and referred to by students themselves, such as the personality of lecturers, who may be more or less approachable, the amount of time spent with them in class, or even the type of room in which lessons are carried out, i.e. a large conference room as opposed to a smaller seminar room.

\subsubsection{Teachers' Perspectives}

Figure 6 shows the address strategies reported by lecturers and teaching assistants when addressing students in ELF face-to-face interaction and email correspondence.

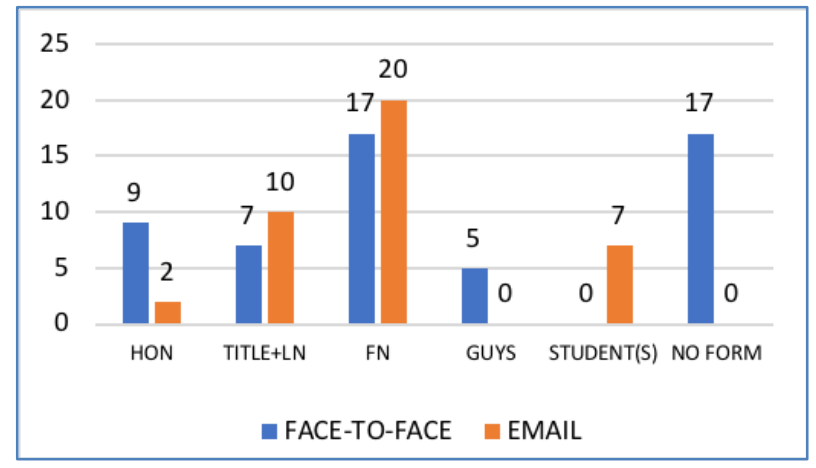

Figure 6. Address strategies to students

Students' first names emerge as the preferred form of address in both face-to-face interaction and emails (17 and 20 informants, respectively), pointing at $\mathrm{T}$-forms as the default strategy employed by teachers. The collective vocative guys (5 informants) and the general term student(s) (7 informants) also occur and can be assimilated with T-forms that add up to the informality of exchanges. At the same time, V-forms are also reported with a relevant frequency in the use of honorifics ( 9 and 2 informants in face-to-face and email exchanges, respectively) and title plus last name ( 7 and 10 informants in face-to-face and email exchanges, respectively). The latter mostly combines the title $D r$ with students' last names and is exclusively reported by Italian lecturers, reflecting the Italian address 
practice of using the title $\mathrm{Dr}$ (Dott. or Dott.ssa in Italian) with people holding at least a bachelor's degree, like the students attending the ELF courses under investigation. Only rarely are the titles $\mathrm{Mr} / \mathrm{Mrs}$ mentioned as an option. Finally, 17 lecturers report not using address forms in class, possibly because the organization of the ELF courses in short didactic modules does not allow them to spend enough time with students to know their names and use them.

When asked to define their relationship with students, lecturers and teaching assistants responded as summarised in Figure 7.

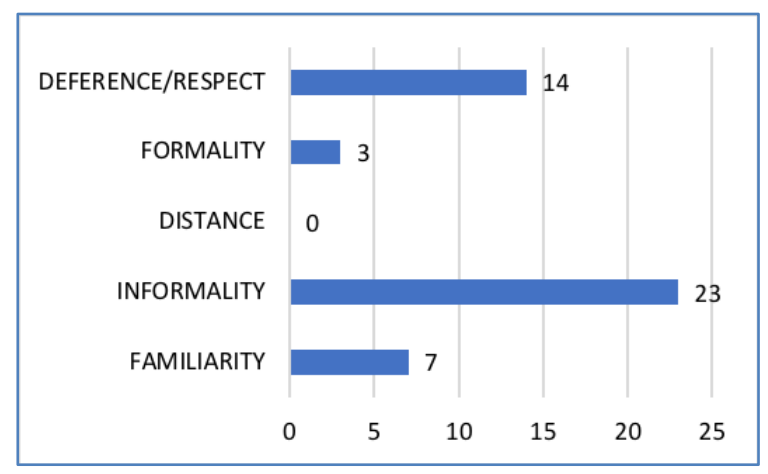

Figure 7. Lecturers' perception of student/lecturer relationship

Informality is the term more frequently used (23 informants), followed by deference/respect (14 informants). Familiarity and formality are selected by few of the teachers ( 7 and 3 informants, respectively), and distance is never reported. The picture emerging from Figure 7 is of generalised informality and friendliness in classroom relations, paralleled by mutual respect between students and teaching staff.

Figure 8 shows lecturers' stance on the use of students' first names. In line with the responses in Figure 6, the great majority of teaching staff members declare the use of students' first names, either from the very beginning (13 informants) or when they know students better (17 informants). Only very few teachers avoid employing first names, because they prefer to maintain a certain level of distance and formality (1 informant) or do not want to cause embarrassment by using an intimate form of address (3 informants).

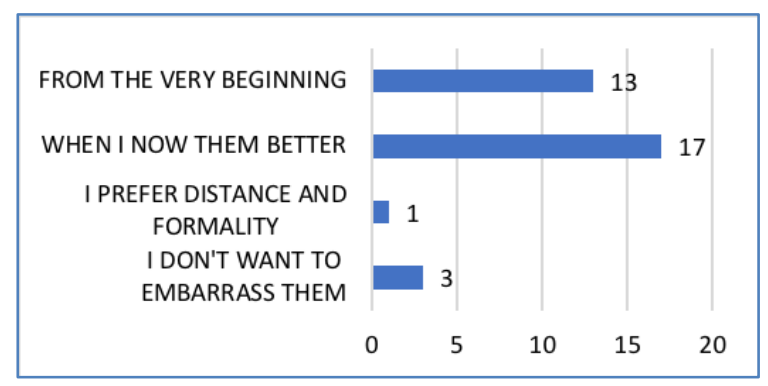

Figure 8. Lecturers' use of students' first names

Conversely, lecturers' reactions to the use of their first name on the part of students are mixed, as can be read from the distribution of responses in Figure 9. On the one hand, some informants report that students use teachers' first names also in their home institution (8 informants) and think that such an address practice is useful in teaching, as informality in class is likely to foster learning ( 9 informants). On the other hand, approximately the same number of lecturers find first names on the part of students too intimate ( 9 informants) and prefer to be addressed more formally with a title or an honorific (11 informants).

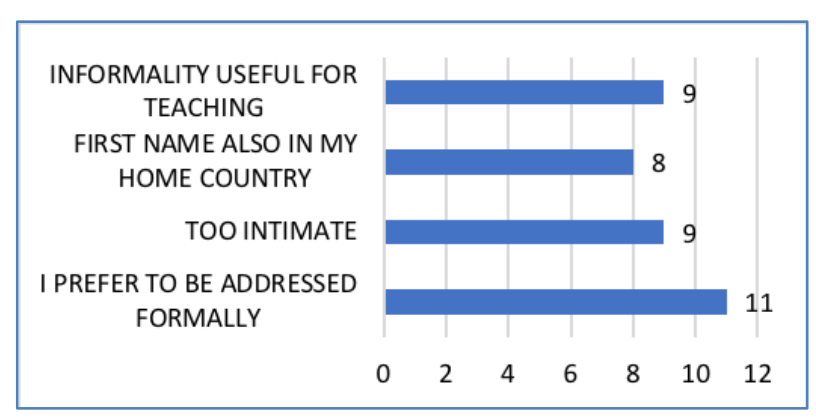

Figure 9. Lecturers' perception of students using first names

Moving to the comments recorded in the last question of the survey, a greater degree of informality again emerges as a distinctive trait of the ELF courses compared to the experiences lecturers have in their home universities.

(9) In my home university, the relations are much more formal. (Male lecturer, France)

(10) The relationship with master's students is more informal and friendly with respect to other courses at the university, because their [i.e. students'] number is reduced, they are more motivated and contacts are more frequent in the course lectures. (Male lecturer, Italy)

(11) Permanent faculty typically addresses the students by first name. This sets the standard and as a guest I tried to follow their example. I have to admit that being used to formalism of my home university, it feels strange for me to call students by their first name. However, I tried to adjust to this to be in line with the customs of the school. (Male lecturer, Switzerland)

(12) I would not say I encourage students to use my first name, but I do not mind if they do. I believe in my situation it is a question of age $-\mathrm{I}$ am of a similar age to many of the students (or in some cases younger!) and so I think it is hard for them to be particularly formal with me. I do not mind if they use my first name as I think in a post-graduate environment it is acceptable. I would expect undergraduate students to call me Dr Carroll (as would be the case in my home country, England). (Female lecturer, UK)

Informality in the ELF courses is fostered by frequent contacts between lecturers and students and is facilitated by the small number of students in the classroom (comment 10). Reduced age difference between interlocutors also seems to play a role in the growing informality (comment 
12). What emerges from the comments, however, are the different reactions to the use of first names in class. To call students by their first names is perceived as unusual by some lecturers who follow more formal approaches in their countries of origin (comment 11), while other informants find the reciprocal exchange of $\mathrm{T}$-forms acceptable at post-graduate level, as it is normal practice also at their home universities (comment 12).

Insightful comments are also made by lecturers on students' behaviour in interpersonal relations. Formality and respect are generally observed in students' choice of address terms and in language use in general, as reported in comments (13) and (14).

(13) There are differences in the behaviour of the students. The majority of them express deference and respect towards your work both in terms of language and actions. (Male lecturer, Italy)

(14) In general, I find students to address me more formally at the beginning, compared with other experiences elsewhere; however, they are ready to switch to informal communication once invited to do so. (Male lecturer, Italy)

Interesting comments are also made on students' cultural backgrounds and how they may affect address practice in the ELF courses.

(15) Just one comment on the different interaction with European and South/Central American students respect to Asian students (mainly Pakistani, Indian). The latter definitely had a more formal interaction with me. It seemed to me that they're also more thankful for the extra time I spent to clarify some point that they didn't get. (Male teaching assistant, Italy)

(16) Usually, students from developing countries are much more respectful than Italian ones, so that I normally avoid familiarity with them and I am more formal. (Male teaching assistant, Italy)

(17) Some students (especially those from Pakistan) refer to me as Prof. Helen (i.e. Prof and first name). I believe this is because they don't really distinguish between first names and surnames in their country and so they just use the first name as a convention. However, they are very respectful and always use "Prof". (Female lecturer, UK)

Comments (15), (16) and (17) reveal that Asian students are particularly sensitive to the expression of deference and respect in academic relations compared to European and Latin American students. This matches some of the observations made by African and Asian students themselves (see comments (4), (5) and (6) above).

\section{Discussion and Conclusions}

In spite of a moderate degree of variation in the address strategies reported by informants, some trends of regularity emerge from the data. V-forms are the default strategies adopted by students in addressing teaching staff members, while $\mathrm{T}$-forms are limited to interactions with teaching assistants, who are however also addressed with V-forms. The opposite distribution of address strategies characterises the responses of lecturers, for whom T-forms are the default choice in addressing students, without excluding a minor use of $\mathrm{V}$-forms.

In terms of reciprocal/non-reciprocal usage of address terms, two major concurrent patterns can be identified: 1) an asymmetrical, non-reciprocal use of address strategies between lecturers and students, in which the former take a more informal and familiar stance, while the latter tend to express deference and respect acknowledging lecturers' social status by means of titles and honorifics; 2) a reciprocal, symmetrical use of $\mathrm{V}$-forms that encodes mutual respect and a higher degree of formality in interpersonal relations.

If pattern 1 has been previously described in the literature as a default address practice in academic interactions in English, for instance in some American universities and partly in some British universities [7,10], pattern 2 has never been reported as a relevant address practice in Anglophone academic institutions and might be distinctive of ELF courses, as a result of the diverse linguacultural composition of participants. The coexistence of several sociopragmatic norms of reference for address may in fact induce participants to keep on the 'safe side' of more formal and respectful address forms, deemed more appropriate in institutional and hierarchical domains of interaction like the academia, thus minimizing the risks of offending the interlocutor.

At the same time, according to the data the use of T-forms is often promoted by permanent teaching staff as part of the policies of the ELF courses and is thought to be conducive to better learning outcomes. While some participants decide to conform to such practice (especially visiting teaching staff), other informants show some resistance to informality, as it is felt to be partially in contrast with their cultural values. It is clearly the case with South Asian, Middle Eastern and African students, who are used to a strict hierarchical organization of society in their home countries and to the expression of deference towards people of higher social status like university professors. This explains students' preference for V-forms, but also the high rate of avoidance strategies reported in the survey (i.e. no use of address forms), which allow students to avoid expressing interpersonal stance overtly. To a lesser extent, a similar position is taken by some teaching staff members, who acknowledge the more respectful attitude shown by students from Asian and African countries and are careful not to address them too informally.

Finally, very few students report that interactions are more formal in the Italian ELF courses than in their home institutions. Once again, reference is made to the 
sociopragmatic norms at work in their native cultures, in particular to the widespread informality and egalitarianism typical of the Australian academic setting [10], and to the friendly and relaxed academic interactions in South American countries.

In conclusion, two apparently competing forces are mainly involved in the management of interpersonal relations and in the choice of address strategies in the ELF courses analysed in this paper, namely deference/respect and informality, which are mostly regulated by participants' cultural backgrounds, previous experience in their home universities, and assumptions about the interlocutor's cultural expectations. Mutual respect and informality, however, do not exclude one another and do not prevent students and teachers from gradually abandoning formality in favour of a closer relationship, thus turning the linguacultural diversity of ELF courses into a challenging opportunity for personal enrichment and professional growth.

\section{REFERENCES}

[1] R. Brown, A. Gilman. The pronoun of power and solidarity. In T. A. Sebeok (ed.) Style in language. Cambridge, Massachusetts: Technology Press of Massachusetts Institute of Technology, 1960, pp. 253-276.

[2] F. Braun. Terms of address: Problems of patterns and usage in various languages and cultures. Berlin: Mouton de Gruyter, 1988.

[3] J. Helmbrecht. Politeness distinctions in pronouns. In M. S. Dryer, M. Haspelmath (eds) The World Atlas of Language Structures Online. Leipzig: Max Planck Institute for Evolutionary Anthropology, 2013, Online available at http://wals.info/chapter/45.

[4] M. Clyne. Pluricentric languages - Introduction. In M. Clyne (ed.) Pluricentric languages. Differing norms in different nations. Berlin: Mouton De Gruyter, 1992, pp. 1-9.

[5] K. Plevoets, D. Speelman, D. Geeraerts. The distribution of $\mathrm{T} / \mathrm{V}$ pronouns in Netherlandic and Belgian Dutch. In K. P. Schneider, A. Barron (eds) Variational Pragmatics. Amsterdam: Benjamins, 2008, pp. 181-209.

[6] R. Vismans. Negotiating address in a pluricentric language: Dutch/Flemish. In C. Norrby, C. Wide (eds) Address Practice as Social Action: European Perspectives. Basingstoke: Palgrave Macmillan, 2015, pp. 13-32.

[7] M. Formentelli. Address strategies in a British academic setting. Pragmatics Vol.19, No.2, 179-196, 2009.

[8] L. Kretzenbacher, J. Hajek, C. Norrby. Address and introductions across two pluricentric languages in intercultural communication. In R. Muhr, C. Amorós Negre, C. Fernández Juncal, K. Zimmermann, E. Prieto, N. Hernández (eds) Exploring linguistic standards in non-dominant varieties of pluricentric languages. Explorando estándares lingüísticos en variedades no dominantes de lenguas pluricéntricas. Frankfurt Am Main: Peter Lang, 2013, pp. 259-274.

[9] A. J. Merrison, J. J. Wilson, B. L. Davies, M. Haugh. Getting stuff done: Comparing e-mail requests from students in higher education in Britain and Australia. Journal of Pragmatics Vol.44, 1077-1098, 2012.

[10] M. Formentelli, J. Hajek. Address practices in academic interactions in a pluricentric language: Australian English, American English, and British English. Pragmatics Vol.26, No.4, 631-652, 2016.

[11] M. Clyne, C. Norrby, J. Warren. Language and human relations. Styles of address in contemporary language. Cambridge: Cambridge University Press, 2009.

[12] L. Kretzenbacher. Perceptions of national and regional standards of addressing in Germany and Austria. Pragmatics Vol.21, No.1, 69-83, 2011.

[13] H. L. Kretzenbacher, D. Schüpbach. Communities of addressing practice? Address in Internet forums based in German-speaking countries. In C. Norrby, C. Wide (eds) Address Practice as Social Action: European Perspectives. Basingstoke: Palgrave Macmillan, 2015, pp. 33-53.

[14] M. Hummel, B. Kluge, M. E. Vázquez Laslop (eds) Formas y fórmulas de tratamiento en el mundo hispánico. México D.F.: El Colegio de México (Centro de Estudios Lingüísticos y Literarios), 2010.

[15] M. E. Placencia, C. Fuentes Rodríguez, M. Palma-Fahey (2015) Nominal address and rapport management in informal interactions among university students in Quito (Ecuador), Santiago (Chile) and Seville (Spain). Multilingua Vol.34, No.4, 547-575, 2015.

[16] C. Norrby, C. Wide, J. Lindström, J. Nilsson. Interpersonal relationships in medical consultations. Comparing Sweden Swedish and Finland Swedish address practice. Journal of Pragmatics Vol.84, 121-138, 2015.

[17] C. Norrby, C. Wide, J. Nilsson, J. Lindström. Address and interpersonal relationships in Finland-Swedish and Sweden-Swedish service encounters. In C. Norrby, C. Wide (eds) Address Practice as Social Action: European Perspectives. Basingstoke: Palgrave Macmillan, 2015, pp. 75-96.

[18] M. Clyne. Some thoughts on pragmatics, sociolinguistic variation, and intercultural communication. Intercultural Pragmatics Vol.3, 95-105, 2006

[19] B. Seidlhofer. Understanding English as a lingua franca. Oxford: Oxford University Press, 2011.

[20] J. Coleman. English-medium teaching in European higher education. Language Teaching Vol.39, No.1, 1-14, 2006.

[21] J. Jenkins. English as a Lingua Franca in the international University. The politics of academic English language policy. London/New York: Routledge, 2014.

[22] B. Wächter, F. Maiworm. English-taught programmes in European higher education. The picture in 2007. Bonn: Lemmens, 2008

[23] B. Wächter, F. Maiworm. English-taught programmes in European higher education. The state of play in 2014. Bonn: 
Lemmens, 2014.

[24] F. Costa, J. Coleman. A survey of English-medium instruction in Italian higher education. International Journal of Bilingual Education and Bilingualism Vol.16, No.1, 3-19, 2013.

[25] S. Campagna, V. Pulcini. English as a medium of instruction in Italian universities. Textus Vol.1, 173-190, 2014.

[26] M. Formentelli. Taking stance in English as a lingua franca. Managing interpersonal relations in academic lectures Newcastle upon Tyne: Cambridge Scholars Publishing, 2017.

[27] J. House. Misunderstanding in Intercultural Communication: Interactions in English as Lingua Franca and the Myth of Mutual Intelligibility." In C. Gnutzmann (ed.) Teaching and learning English as a global language. Tübingen: Stauffenburg, 1999, pp. 73-93.

[28] U. Pölzl. Signalling cultural identity: The use of L1/Ln in ELF. VIEWS: Vienna English Working Papers Vol.12, No.3-23, 2003.

[29] T. Klimpfinger. 'Mind you sometimes you have to mix'. The role of code-switching in English as a lingua franca. VIEWS: Vienna English Working Papers Vol.16, No.2, 36-61, 2007.

[30] U. Pölzl, B. Seidlhofer. In and on their own terms - the habitat factor in English as a lingua franca interactions. International Journal of the Sociology of Language Vol.177, 150-176, 2006.

[31] C. Meierkord. 'Language stripped bare' or 'linguistic masala'? Culture in lingua franca conversation. In K. Knapp, C. Meierkord (eds) Lingua franca communication. Frankfurt am Main: Peter Lang, 2002, pp. 109-133.

[32] J. Gumperz. The speech community. In A. Duranti (ed.) Linguistic Anthropology: A reader. Oxford: Blackwell Publishers, 1968, pp. 66-73.

[33] E. Wenger. Communities of practice. Learning, meaning and identity. Cambridge: Cambridge University Press, 1998.

[34] M. Cook, (2014) Beyond T and V - Theoretical reflections on the analysis of forms of address. American Journal of Linguistics Vol.3, No.1, 17-26, 2014.

[35] S. M. Burt. 'There's not a lot of negotiation'. Address terms in an academic department. In M. Terkourafi (ed.) Interdisciplinary perspectives on im/politeness. Amsterdam: John Benjamins Publishing Company, 2015, pp. 71-90.

[36] S. K. Wright. Forms of address in the college classroom. In W. Ahrens, S. Embleton, A. Lapierre (eds) Names in multilingual, multicultural and multiethnic contact. Proceedings of the $23^{\text {rd }}$ International Congress of Onomastic Sciences. Toronto: York University, 2009, pp. 1079-1087.

[37] F. Bargiela, C. Boz, L. Gokzadze, A. Hamza, S. Mills, N. Rukhadze. Ethnocentrism, politeness and naming strategies. Working papers on the web 3, 2002, Online available at http://extra.shu.ac.uk/wpw/politeness/bargiela.htm 